\title{
A ética no Direito ${ }^{1}$
}

José Henrique Rodrigues Torres

Professor da Pontifícia Universidade Católica de Campinas

Juiz de Direito

\section{Resumo}

O artigo debate o alcance da conceituação de ética no campo social e na área jurídica. Analisa as transformações sociais e políticas da sociedade capitalista mundial e as peculiaridades dos movimentos sociais e políticos do Brasil recente. Destaca como fundamental desafio ético do Direito, diante da prevalência da ideologia capitalista dominante a necessidade de aproximar o Direito da realidade social e garantir, no plano material, os direitos existentes no plano meramente formal. Debate a necessidade de formação dos agentes sociais e profissionais do Direito na compreensão da emergência histórica e identidade dos novos direitos sociais. Destaca a premissa de que o futuro da humanidade depende do resultado do antagonismo entre dois sistemas: o sistema capitalista e o sistema dos direitos humanos. Afirma que a base ideológica da política criminal da intolerância é sustentada pelo discurso econômico-transnacional, que concebeu o movimento de Lei e Ordem, que estabelece uma política de guerra aos inimigos, selecionados das classes subalternizadas, e mantém a opção por um estado de exceção permanente. Considera que muitos juristas chegam a afirmar que a criminalização das condutas deve prevalecer na guerra contra as drogas, na preservação da vida, no enfrentamento do abortamento, na garantia da segurança individual e, ainda, no enfrentamento das questões relacionadas com o meio ambiente. Conclui que a nova postura pedagógica necessária deve ser o debate sobre valores, que tem como fundamento a dignidade humana, que se constitui no fundamento da vida ética. E o Direito não pode ignorar isso. A busca da felicidade dá sentido à existência humana. Mas não se trata da busca da felicidade individualista, que o sistema capitalista exorta. A felicidade há de ter um sentido social. Felicidade e alteridade, nesse sentido, são palavras que se aproximam tanto, na concepção da ética, que poderíamos considerá-las sinônimas. Com efeito, é preciso romper com o imobilismo e transformar o mundo, fazendo prevalecer os princípios do sistema dos direitos humanos. Esse é o compromisso Ético do Direito.

Palavras-chave: Ética; Direito; Educador.

\footnotetext{
${ }^{1}$ Participação em mesa redonda do I Simpósio Nacional sobre Política, Ética e Educação (I POIETHOS). Campinas, 13 de junho de 2008.
} 
"Há um tempo em que é preciso abandonar as roupas usadas, que já têm a forma do nosso corpo, e esquecer os nossos caminhos, que nos levam sempre aos mesmos lugares. É o tempo da travessia: e, se não ousamos fazê-la, teremos ficado, para sempre, à margem de nós mesmos.”

\section{Fernando Pessoa}

I nicialmente, devo agradecer aos organizadores deste evento, especialmente ao Dr. Gustavo Bolliger e ao Prof. César Nunes, pelo gentil e honroso convite que me fizeram para participar desta mesa e desfrutar da companhia e do conhecimento dos professores .Marcos Reigota, René José Trentin Silveira e Silvio Donizetti de Oliveira Gallo.

Desculpem-me, no entanto, por esse exórdio abrupto, mas o tempo urge.

Senhores e senhoras, recentemente, eu participei de um Simpósio sobre psico-oncologia, aqui mesmo na UNICAMP, convidado para discutir alguns casos médicos, relacionados, em especial, com a terminalidade da vida e a conduta médica.

E algo deixou-me muito impressionado naquele simpósio, e até mesmo constrangido, quando recebi os casos para estudo e as questões propostas para enfrentamento.

Logo no primeiro caso em discussão, os organizadores colocaram duas questões em discussão: (1) "os procedimentos adotados foram corretos sob o aspecto social e humano?”; e (2) “os procedimentos adotados foram corretos sob o aspecto legal e jurídico?”.

Como os senhores e as senhoras podem perceber facilmente, essas duas perguntas, que certamente não tinham a intenção de constranger-me, deixaram-me em uma situação extremamente perturbadora e provocaram uma imediata e inevitável reflexão.

Afinal, o que é correto do ponto de vista legal ou jurídico pode não ser correto do ponto de vista social ou humano? É possível que determinada 
conduta seja aprovada sob o aspecto humano ou social e, ao mesmo tempo, desaprovada ou censurada sob o aspecto jurídico ou legal? Enfim, o direito não tem que estar fundamentado no social e no humano?

E, agora, neste encontro, parece-me que novamente esse dilema volta a me constranger e a desafiar a minha reflexão. Existe realmente uma ética social distinta de uma ética do Direito? É possível afirmar a existência de uma ética ambiental, de uma ética chamada bioética e de uma ética do Direito, como coisas distintas, cada qual com as suas características específicas, aplicáveis de forma diferente, com base em princípios e fundamentos distintos para cada situação?

Pois, bem, nesses últimos dias eu refleti muito sobre isso tudo.

Aliás, lembrei-me muito de Procusto, aquele sujeito que, de acordo com a mitologia grega, capturava os invasores de suas terras e os levava para casa, onde os colocava em uma de suas camas: uma grande e outra pequena. Entretanto, se o forasteiro fosse pequeno, Procusto o colocava na cama grande e o esticava até que coubesse perfeitamente na extensão do leito. Mas, se o "hóspede” fosse grande, o "gentil” Procusto cuidava de acomodá-lo na pequena cama e cortava as suas pernas, para que o forasteiro coubesse nos limites estabelecidos por aquele diminuto catre. Como se vê, o corpo do forasteiro tinha que ser adequado ao tamanho da cama. Eis, portanto, a questão que a metáfora desse mito provoca: o Direito foi feito para a vida ou a vida deve adequar-se ao Direito, como o forasteiro no leito de Procusto?

E, há alguns dias, enquanto eu refletia sobre todos esses problemas, sobre todos esses questionamentos, aconteceu-me um fato inusitado. E eu gostaria de compartilhar essa experiência "metafísica” com todos e todas que me ouvem com tanta atenção e tolerância.

Há alguns dias, eu estava indo para o Fórum, para vestir a minha toga e salvar a humanidade, como faço todos os dias com os meus superpoderes judiciais, quando liguei o rádio do meu carro e, envolto nos meus pensamentos, de repente percebi que estava tocando uma música que 
chamou a minha atenção: lá estava o Zeca Pagodinho cantando: "Deixa a vida me levar. Vida leva eu”. Fiquei perturbado com aquela letra. Mudei a estação do rádio. E foi então que aconteceu algo inusitado. Lá estava, em outra estação do meu rádio, o Jota Quest cantando: “Eu vou deixar a vida me levar”. Vejam só: um pagode, um rock, mas o mesmo tema a me perturbar. Pensei comigo: só falta agora eu mudar novamente de estação e encontrar o nosso querido Paulinho da Viola cantando "O Timoneiro”: “Não sou eu quem me navega. Quem me navega é o mar”. Desliguei o rádio imediatamente. Parecia uma provocação. Justamente num momento em que eu estava refletindo sobre o mito de Procusto, sobre a Ética no Direito, sobre a Ética Social, sobre a Ética na Política, sobre a Ética na Educação, e especialmente sobre a possibilidade ou não do imbricamento de tudo isso, surgiu essa proclamação a me atormentar: "Deixa a vida me levar".

Senhores e senhoras, será que as pessoas deste meu país, será que os professores, os políticos, os educadores, os cientistas, os juízes e os atores jurídicos também estão pensando em deixar a vida levá-los assim passivamente?!

Foi então que me socorreu uma lembrança salvadora. Lembrei-me do Lenine cantando “Todos os caminhos”: “Nunca se deixe levar”. Isso, para mim, sem querer fazer nenhum trocadilho, já foi um confortante lenitivo. Mas, lembrei-me, também, do Geraldo Vandré, que, em plena ditadura militar, cantou: “Quem sabe faz a hora, não espera acontecer”.

Senhoras e senhores educadores, será que os cidadãos deste meu tempo realmente querem "inventar uma nova canção, que venha nos trazer o sol da primavera”, como canta o Beto Guedes?! Ou será que nós estamos deixando a vida nos levar por aí impunemente?! Será que há coisas para serem enfrentadas e transformadas? Nós queremos realmente transformar o mundo?! Ou será que nós estamos ficando predispostos à abulia?! Afinal, como canta o Pato Fu, “esse mundo é tão perfeitim e nóis quer mudar o mundo!”. Aliás, o Cazuza cantava que “os seus heróis 


\section{morreram de overdose" e que "aquele garoto que queria mudar o mundo, agora assiste a tudo em cima do muro”.}

Afinal, onde estamos nós?! Em cima do muro?! Ou queremos, juntos, mudar o mundo?! Há algo para ser mudado?! Há algo de podre no reino da Dinamarca?! Há algo de errado neste mundo “perfeitim”?!

Neste momento histórico desconfortável, nós vemos prevalecer e agigantar-se, como um Leviatã, uma ideologia capitalista neoliberal, cruel e avassaladora, que valoriza, acima de qualquer coisa, os interesses econômicos, patrimoniais e financeiros, que incentiva o lucro, a competição e o individualismo, que idolatra o capital especulativo e volátil, que despreza, exclui e marginaliza os seres humanos e que produz e reproduz a discórdia de Eris, a violência e o desencontro.

E é nesse contexto social e político, vivenciado sob a égide da ideologia capitalista, que o Direito está enfrentando, atualmente, desafiantes questões, de extrema relevância histórica, e que podem acarretar imensas consequências para a convivência humana e para a felicidade da vida social.

Lembro-me, aliás, neste momento, de alguns fatos que têm sido veiculados pela mídia e provocado muita discussão e embates intermináveis, especialmente no campo da ética, com diversos e antagônicos enfoques políticos, econômicos, morais e ideológicos.

Por exemplo, como observou Boaventura de Souza Santos, em artigo publicado recentemente em um jornal paulista de grande circulação, a demarcação dos territórios indígenas, a regularização dos territórios quilombolas e até mesmo a questão das cotas são problemas que não podem ser enfrentados pelo sistema jurídico, pelos juízes, pelos profissionais do Direito, sem que seja considerada a realidade histórica em que estamos mergulhados, realidade essa decorrente “de uma política embasada em profundas contradições e produzida por uma histórica usurpação violenta dos territórios originários dos povos indígenas e por uma continuada exploração dos escravos” e dos segmentos sociais subalternizados. 
E não se olvide, também, as discussões sobre a clonagem, sobre o aproveitamento das células tronco-embrionárias para pesquisas, sobre a criminalização do porte de entorpecente e sobre a descriminalização do aborto por malformação fetal, que inviabiliza a vida extrauterina, temas esses que extrapassaram os limites dos debates acadêmicos, científicos ou jornalísticos para exigir um posicionamento do Poder Judiciário.

Mas, senhoras e senhores, nós não podemos nos olvidar que o direito e a sociedade, ao enfrentarem esses embates, navegam por um mar revolto, encapelado, atormentado pelas procelas da desigualdade e de uma histórica injustiça social, caracterizada especialmente pela flagrante omissão dos Estados.

Como todas e todos aqui sabem muito bem, nós acabamos de sair de um século que, segundo Eric Hobsbawm, foi o século mais curto da história da humanidade e ficou caracterizado por uma terrível "negligência social”. Lembrem-se de que, no século XX, enfrentamos duas terríveis guerras, que, como nunca antes havia ocorrido, infligiram ao ser humano, no âmbito mundial, um inesquecível flagelo e ferimentos profundos que insistem em latejar e teimam em não cicatrizar.

É por isso que, depois da segunda Grande Guerra, as nações têm feito um enorme esforço para criar um sistema universal de proteção, mas de proteção do ser humano: criamos a ONU; produzimos Convenções e Tratados Internacionais; e reconhecemos a existência de um sistema de Direitos Humanos (internacionais, indivisíveis, obrigatórios e vinculantes), exatamente na tentativa de colocar os Estados a serviço dos seres humanos e de sua dignidade.

Os direitos humanos, assim, nesses últimos anos, foram se expandindo, foram se acumulando e se fortalecendo. Mas foi necessário o enfrentamento de muita resistência. Aliás, até hoje, o que desvela de forma sutil essa resistência, muita vez inconsciente, ainda há quem insista, por exemplo, em dizer que construímos direitos de primeira, de segunda e de terceira geração, como se fosse possível fragmentar o próprio ser humano. 
Na realidade, ainda há quem acredite em "gerações de direitos humanos”, empolgados, até mesmo sem o saber, por uma ideologia reacionária, que faz prevalecer uma visão atomizada dos direitos humanos, prestando um desserviço à humanidade, como diz Cançado Trindade.

Entretanto, apesar de tanta resistência, criamos, enfim, um sistema de direitos que não deve reger relações entre iguais, mas que deve operar, sim, em defesa dos mais débeis, dos mais fracos.

Elaboramos a Declaração Universal dos Direitos Humanos em 1.948. Em 1.966, fizemos o Pacto Internacional dos Direitos Civis e Políticos. E, em 1.976, dez anos depois, conseguimos fazer valer o Pacto Internacional dos Direitos Econômicos, Sociais e Culturais. Mas, a garantia efetiva desses direitos ainda é um grande problema.

E há uma explicação para isso. A ONU, em meados do século passado, idealizou um projeto para o reconhecimento dos Direitos Civis e Políticos (direito à liberdade, à igualdade formal, à manifestação livre de opinião, à liberdade de imprensa, ao casamento livre, a associação, ao nome, a não ser submetido a tortura, a não ser escravizado, à segurança pessoal, etc.). Mas, a ONU também pretendia que fossem reconhecidos e assegurados, simultaneamente, os Direitos Econômicos, Sociais e Culturais (direito à alimentação, à educação, à saúde, à previdência social, à participação cultural, etc). Todavia, naquele momento histórico, e isso ninguém ignora, o mundo estava dividido: o Ocidente Capitalista e o Oriente Socialista digladiavam-se. E houve, então, um embate ideológico a respeito da eficácia e da efetividade da garantia desses Direitos Humanos, reconhecidos e proclamados, depois de tantos esforços, para garantir a dignidade das pessoas e os direitos dos mais frágeis. De um lado, o Ocidente Capitalista sustentava que os Direitos Civis e Políticos eram auto-aplicáveis, mas que os Direitos Econômicos, Sociais e Culturais, por óbvias razões ideológicas, eram apenas programáticos e de implantação progressiva, o que significava que a sua efetividade dependia das prioridades econômicas dos Estados. E, do outro lado, o Oriente Socialista sustentava exatamente o 
contrário: os Direitos Econômicos, Sociais e Culturais seriam autoaplicáveis, enquanto os Direitos Civis e Políticos seriam programáticos, de implantação progressiva. Como se vê, ficamos diante de duas visões antagônicas, mas ambas igualmente fragmentadoras. E, infelizmente, acabou prevalecendo essa visão fragmentadora. E, o que é pior, venceu o embate a ideologia ocidental capitalista. É por isso que, hoje, ainda vigora essa interpretação terrível a respeito dos direitos fundamentais: os Direitos Civis e Políticos são considerados autoaplicáveis, enquanto os Direitos Econômicos, Sociais e Culturais, como o direito à educação, à habitação, à alimentação, à saúde, à cultura, são considerados programáticos, de implantação progressiva, o que os coloca na dependência das prioridades econômicas dos Estados.

Daí, obviamente, a legitimação jurídica e ideológica da omissão dos Estados com relação à garantia dos Direitos Econômicos, Sociais e Culturais,

E nós vamos deixar essa correnteza nos levar?!

Na realidade, todos os direitos humanos, civis, políticos, sociais, culturais ou econômicos, são inseparáveis e deveriam ser garantidos e implantados imediatamente como condição fundamental para a prevalência da felicidade social e da dignidade das pessoas. E nenhum desses direitos poderia ser considerado como meramente programático, pois uns não representam nada sem os outros!

O Brasil, recentemente, incorporou em sua Constituição Federal praticamente todos esses direitos humanos, de forma expressa, e a dignidade humana foi elegida como espinha dorsal de nosso sistema jurídicoconstitucional.

Contudo, esses direitos, em especial os econômicos, sociais e culturais, estão sendo garantidos apenas e tão-somente no plano formal, principalmente porque nós, juristas, profissionais do direito, legitimando a omissão do Estado, proclamamos equivocadamente o caráter programático desses direitos fundamentais. Obviamente, essa postura jurídica justifica e 
legitima uma terrível omissão quanto à garantia dos direitos fundamentais no plano material.

Aliás, isso me faz lembrar de Ruy Guerra, o poeta angolano que, radicado no Brasil, compôs, com Chico Buarque de Holanda, a música “Fado Tropical”, que, em um de seus verso, diz o seguinte: “Se a mão fica distante do coração, é porque existe uma grande distância entre intenção e gesto”. Eis, portanto, o grande desafio ético do Direito, diante da prevalência daquela fragmentadora ideologia capitalista: aproximar a mão do coração, aproximar o Direito da realidade social, garantir, no plano material, os direitos existentes no plano meramente formal. É por isso que Norberto Bobbio, em sua obra “A era dos Direitos”, afirma que “o problema fundamental em relação aos direitos do homem, hoje, não é tanto de justificá-los, mas o de protegê-los. Trata-se de um problema não filosófico, mas, sim, político”.

Assim, ouso hoje afirmar, lembrando-me dos ensinamentos de Fábio Conder Comparato, que o futuro da humanidade depende do resultado do antagonismo entre dois sistemas: o sistema capitalista e o sistema dos direitos humanos. Aliás, vale a pena lembrar do que Comparato diz a respeito desse antagonismo que definirá o destino da humanidade: "no capitalismo vigora, sem exceções, o princípio da realização do interesse próprio e imediato de cada indivíduo, grupo social ou povo, sem a menor consideração pelo bem comum da coletividade e das futuras gerações (...) Os rendimentos de capital na formação do produto mundial não param de aumentar, enquanto os rendimentos do trabalho, assalariado ou autônomo, continuam a decrescer. (...) O novo sistema de transnacionalidade empresarial estabelece relações de senhorio e servidão entre as empresas localizadas em várias partes do mundo (...) as empresas servas são obrigadas a operar em sistema de dumping social e negação dos mais elementares direitos trabalhistas. (...) e, em face do fortalecimento do capitalismo financeiro, está ocorrendo uma enorme redução dos investimentos produtivos, em relação ao total das riquezas produzidas”. Mas, felizmente, acrescenta Comparato, “em contraste com o desnorteamento e o caráter 
mundialmente predatório do capitalismo, assistimos à progressiva formação do conjunto de direitos humanos (...)”.

Senhoras e senhores, o modo de produção capitalista, apesar dos evidentes sinais de declínio, ainda prevalecerá por algum tempo, talvez por muitos anos ainda, e o que nós estamos vendo, de forma indisfarçável, é que os Estados não controlam mais o poder econômico. Na realidade, é o poder econômico, especialmente concentrado nas mãos de alguns conglomerados multinacionais, que controla e subordina os Estados e as políticas públicas, estrangulando-as e acarretando terríveis prejuízos para os seres humanos que habitam este país e os demais países do chamado terceiro mundo, especialmente os mais frágeis e oprimidos.

Aliás, peço vênia a todas e todos para lembrar o resultado de uma recente pesquisa realizada no Brasil, sobre a segurança alimentar (PNDA pesquisa nacional por amostra em domicílio): 7,7\% da população brasileira (14 milhões de pessoas) viviam em domicílios que foram visitado pela fome pelo menos um dia no ano de 2004, enquanto 72 milhões de habitantes deste país (39.8 \%) ficaram vulneráveis à fome, em maior ou menor grau, naquele ano.

E é exatamente nesse contexto histórico, político, social e econômico que nós estamos refletindo, hoje, sobre Ética e, especialmente, sobre a Ética no Direito, ou mesmo sobre a Ética na aplicação do Direito.

Nesse contexto, por exemplo, a base ideológica da política criminal da intolerância é sustentada pelo discurso econômico-transnacional, que concebeu o movimento de Lei e Ordem, que estabelece uma política de guerra aos inimigos, selecionados das classes subalternizadas, e mantém a opção por um estado de exceção permanente, que encanta até mesmo a esquerda. Enfim, estamos convivendo com a prevalência de uma ideologia de Defesa Social ou de Segurança Nacional repaginada, para usar uma expressão da moda, legitimadora da militarização do sistema de controle social. E o modelo repressivo das políticas públicas está sendo confundido com o modelo promocional. 
Aliás, muitos juristas chegam a afirmar que a criminalização das condutas deve prevalecer na guerra contra as drogas, na preservação da vida, no enfrentamento desse problema social e sanitário que é o abortamento, na garantia da segurança individual e, ainda, no enfrentamento das questões relacionadas com o meio ambiente, porque teria a criminalização, vejam só, uma função pedagógica. Todavia, olvidam-se esses juristas, e até mesmo legisladores, obnubilados pela ideologia capitalista, que o direito penal, essencialmente repressivo, não tem função promocional.

E também há juristas que afirmam, inclusive, que o Poder Judiciário existe para garantir a ordem, não para fazer Justiça, exatamente como disse Creonte ao condenar Antígona ao sepultamento em vida.

Como se vê, é muito fácil explicar o porquê da proibição da Marcha da maconha, a insistência pela mantença da criminalização do aborto, a constante criminalização dos movimentos sociais, a flexibilização dos direitos trabalhistas e até mesmo o combate aos programas de redução de danos causados pelas drogas. É a prevalência de uma política essencialmente proibitivista, que exclui as políticas promocionais.

Não, nós não podemos deixar essa correnteza nos levar. É preciso dizer, como o poeta português José Régio: “Não sei por onde vou, não sei para onde vou, mas sei que não vou por aí”.

E todos e todas que participam deste Simpósio sobre Ética sabem perfeitamente que estamos diante de uma questão relacionada essencialmente a valores.

Como é sabido, Moral e Ética são palavras com a mesma raiz etimológica, uma derivada do latim, outra do grego, mas ambas nos remetem ao questionamento dos valores ligados à normatização da conduta humana. Aliás, como ensina Yves De La Taille, muita vez nós pronunciamos Ética para não pronunciar Moral, mas não escapamos do problema dos valores. 
Lembram-se os senhores e as senhoras da disciplina Educação Moral e Cívica, imposta a todos nós pelo sistema educacional do recente período autoritário que afligiu esta nação? Pregava-se, então, a imposição de valores e exigia-se uma resignação incondicionada. Cobra-se, naquele momento obscuro de nossa história, a obediência cega a determinados valores morais.

Hoje, todavia, uma nova postura pedagógica precisa e deve ser adotada.

O discurso maniqueísta do embate entre o bem e o mal não se coaduna mais com as perspectivas do Estado de Direito Democrático, que tem como fundamento a dignidade humana. Aliás, a dignidade é exatamente o fundamento da vida ética. E o Direito não pode ignorar isso.

Gilgamesh, o rei semi-lendário de Uruk, na Mesopotâmia, ao chegar às margens das Águas Mortais, foi advertido pela Deusa Siduri de que jamais poderia atingir a imortalidade. E, assim, descobriu que o melhor seria voltar para a sua cidade, desfrutar os prazeres simples da vida, cuidar ternamente de sua progenitura, buscar a felicidade no convívio com os seus entes queridos e viver uma vida harmoniosa e pacífica com o seu povo. Esse é o sentido ético da vida. E o direito não pode divorciar-se da vida e desse seu sentido ético. E o poeta Mario Quintana percebeu isso com muita sabedoria ao afirmar, em um de seus versos, que “a vida é uma fogueira; quem importa restarem cinzas, se as chamas foram altas e belas?” A vida ética é a fogueira que ilumina e aquece.

A busca da felicidade dá sentido à existência humana. Mas não se trata da busca da felicidade individualista, que o sistema capitalista exorta. A felicidade há de ter um sentido social. Felicidade e alteridade, nesse sentido, são palavras que se aproximam tanto, na concepção da ética, que poderíamos considerá-las sinônimas.

Assim, se a ética é a arte de viver, se é uma fogueira com chamas altas e belas, se é a busca da felicidade com responsabilidade social, as faculdades de Direito deveriam, acima de qualquer outra coisa, formar profissionais preparados para respeitar a dignidade humana antes de 
qualquer outra coisa, sempre com fundamento na alteridade.

É verdade que no Estado de Direito Democrático não se pode exigir virtudes, ou seja, não se pode exigir que as pessoas sejam gratas, prudentes, generosas ou corajosas. Mas é imprescindível trabalhar essas virtudes. E aqui exsurge uma inegável oportunidade de participação dos educadores na construção de um mundo ético.

Nós não podemos nos olvidar que ser corajoso para opor-se à arbitrariedade ou à desigualdade constitui um dever ético. E também é dever ético ser humilde para reconhecer que não foi justo. E é preciso ser prudente para garantir a justiça. Para cumprir o dever ético é preciso disposição de caráter. É preciso ser corajoso para dialogar. E é preciso não prescindir do afeto e dos sentimentos, pois, como diz Carlos Drumond de Andrade, “as leis não bastam, os lírios não nascem das leis”. Mas também é preciso lembrar que coragem não é virilidade, nem violência. E é preciso ser generoso e humilde para aceitar o outro. E eu não estou me referindo a uma amorfa e acrítica resignação. Aliás, Ernesto Sabato, em sua recente obra “A resistência”, conseguiu, com a sabedoria dos grandes escritores, fazer uma perfeita distinção entre aceitação e resignação. Diz Sabato que "resignar-se é uma covardia, é o sentimento que justifica o abandono daquilo pelo qual vale a pena lutar; de certo modo, é uma indignidade. A aceitação é o respeito pela vontade do outro, seja ele um ser humano ou o próprio destino. Não nasce do medo, como a resignação; a aceitação é como um fruto”.

Portanto, eu não estou falando em resignação, mas, sim, em aceitação democrática do outro. Somente com plena compreensão e democrática aceitação do outro poderão os profissionais do direito cumprir o seu dever ético no sistema democrático em que vivemos. Enfim, somente um direito Ético, fundamentado na dignidade, no respeito, na alteridade e na solidariedade, pode construir um Direito não apenas formal, mas composto por normas de substância, que legitimam a decisão de Antígona.

É por isso que os atores do sistema jurídico, no Estado de Direito Democrático, não devem sujeitar-se cegamente à lei. Com compromisso 
ético, devem sujeitar-se à lei apenas enquanto válida, ou seja, devem sujeitar-se á lei apenas e tão-somente enquanto a lei for coerente com os valores consagrados pelo sistema de Direitos Humanos, valores esses fundamentais à convivência humana.

Decididamente, cabe a todos os atores jurídicos afirmar todos os dias: não vou deixar a vida me levar.

Com efeito, é preciso romper com o imobilismo e transformar o mundo, fazendo prevalecer os princípios do sistema dos direitos humanos.

Esse é o compromisso Ético do Direito.

E, se alguém acredita que isso não é possível, eu termino a minha reflexão invocando um verso do poeta Mario Quintana: “Se as coisas são inatingíveis, não é motivo para não querê-las. Que tristes os caminhos, não fora a mágica presença das estrelas”.

Não vamos deixar a vida nos levar.

“Transformar o mundo é tão difícil quanto possível.”

Paulo Freire 